\title{
Destination therapy with ventricular assist devices for patients with dystrophinopathies: A new way of life
}

\author{
Christian Pizarro, MD
}

\footnotetext{
From the Departments of Surgery and Pediatrics, Sidney Kimmel Medical College at Thomas Jefferson University, Philadelphia, Pa; and Nemours Cardiac Center, Alfred I. duPont Hospital for Children, Wilmington, Del.

Disclosures: Author has nothing to disclose with regard to commercial support.

Received for publication Oct 27, 2016; accepted for publication Oct 27, 2016; available ahead of print Dec 16, 2016

Address for reprints: Christian Pizarro, MD, Professor of Surgery and Pediatrics, Sidney Kimmel Medical College at Thomas Jefferson University, Chief, Cardiothoracic Surgery, Alfred I. duPont Hospital for Children, 1600 Rockland Rd, Wilmington, DE 19803 (E-mail: Christian.Pizarro@nemours.org).

J Thorac Cardiovasc Surg 2017;153:667-8

$0022-5223 / \$ 36.00$

Copyright (C) 2016 by The American Association for Thoracic Surgery

http://dx.doi.org/10.1016/j.jtcvs.2016.10.071
}

Dystrophinopathies are X-linked disorders associated with progressive skeletal muscle weakness and dilated cardiomyopathy. In the current era, end-stage heart failure is the predominant cause of death in this population. The coexistence of progressive skeletal and cardiac muscle compromise creates a real challenge to identify the culprit for the progressive and unrelenting functional decline affecting these patients. Although selected individuals with preserved skeletal muscle function and clear evidence of end-stage heart failure have received transplants with good outcomes, this situation constitutes the exception, as most patients are not considered suitable candidates because of advanced skeletal muscle compromise, lack of clear distinction between cardiac muscle compromise, skeletal muscle compromise, or a combination of both.

The successful and widespread use of ventricular assist devices (VADs) as destination therapy has opened the door to consider this novel management option for individuals with a dystrophinopathy affected by significant cardiac muscle compromise. The report in this issue of the Journal by Perri and colleagues ${ }^{1}$ provides further evidence in favor of considering the use of VADs, potentially changing the current management paradigm for these patients. In light of potential candidacy for VAD support, differentiation between worsening functional capacity secondary to heart failure as opposed to progression of the skeletal muscle pathology is a difficult but essential process to identify those individuals who would benefit the most from a transplant or VAD support. The use of VAD therapy not only offers the opportunity to evaluate patients for transplant candidacy once heart failure has been resolved but, as suggested by Perri and collagues, ${ }^{1}$ it can also provide effective and durable support as destination therapy for those not eligible for transplantation.

The small size of the new generation of pumps offers important advantages when treating smaller patients and

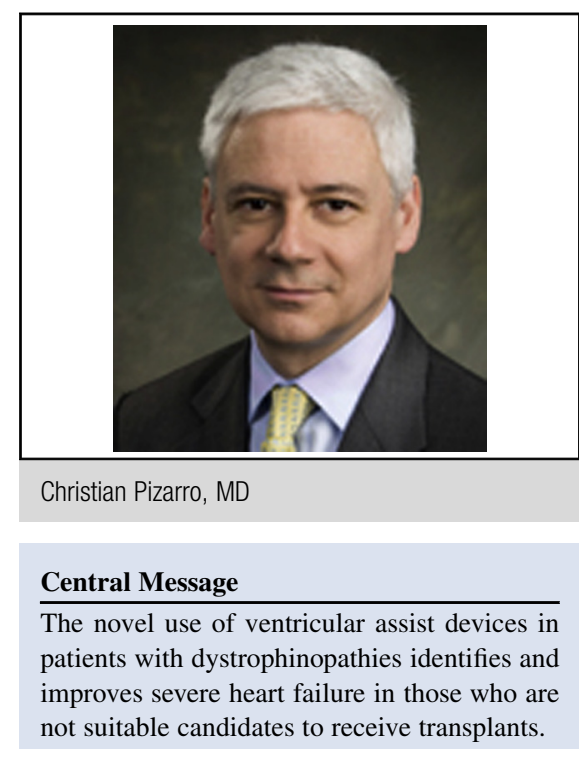

See Article page 669.

those with skeletal muscle disease, expanding the applicability of this type of support. Moreover, the intrapericardial placement can mitigate the impairment of diaphragmatic function associated with large paracorporeal cannulas, leading to preservation of respiratory mechanics, which is essential in patients with muscular dystrophy. Finally, the intracorporeal nature of the VAD system used is essential for destination therapy and to achieve the ultimate goal of improving the quality of life for these patients.

It should be apparent from this experience and from others $^{2,3}$ that the success of VAD support as destination therapy requires more than just the procedure of VAD placement. It requires a comprehensive, multidisciplinary effort, including early and aggressive physical therapy to increase mobility and optimize respiratory function, aggressive nutritional support, careful management of anticoagulation, as well as resolution of any social and educational issues that may influence compliance.

The feasibility of treating patients affected by muscular dystrophy and severe heart failure effectively with VAD support has been demonstrated. In fact, in some cases, this may be a superior alternative to transplantation. On the basis of the data of Perri and colleagues, ${ }^{1}$ it seems possible that with further refinements in management, patient selection, and early evaluation, VAD support could become one of the most effective management strategies 
to enhance the quality of life for this challenging group of patients.

\section{References}

1. Perri P, Filippelli S, Adorisio R, Iacobelli R, Iodice F, Testa G, et al Left ventricular assist device as destination therapy in cardiac end-stage dystrophinopathies: midterm results. J Thorac Cardiovasc Surg. 2017;153: 669-74.

2. Davies RD, Priest M, Pizarro C. First use of an intra-pericardial continuous flow ventricular assist device in a child with muscular dystrophy. Cardiol Young. 2015; 25:184-6.

3. Miera O, Potapov EV, Redlin M, Stepanenko A, Berger F, Hetzer R, et al. First experiences with the HeartWare ventricular assist system in children. Ann Thorac Surg. 2011;91:1256-60. 